\title{
Protein Encapsulation of Experimental Anticancer Agents 5F 203 and Phortress: Towards Precision Drug Delivery
}

This article was published in the following Dove Press journal: International Journal of Nanomedicine

\author{
Alastair F Breen' \\ David Scurr (D)' \\ Maria Letizia Cassioli ${ }^{1}$ \\ Geoffrey Wells (iD) ${ }^{2}$ \\ Neil R Thomas $\mathbb{1 D}^{3}$ \\ Jihong Zhang ${ }^{4}$ \\ Lyudmila Turyanska (iD ${ }^{5}$ \\ Tracey D Bradshaw $\mathbb{D}^{\prime}$ \\ 'Centre for Biomolecular Sciences, \\ School of Pharmacy, University of \\ Nottingham, Nottingham NG7 2RD, UK; \\ ${ }^{2} \mathrm{UCL}$ School of Pharmacy, University \\ College London, London, UK; ${ }^{3}$ Centre \\ for Biomolecular Sciences, School of \\ Chemistry, University of Nottingham, \\ Nottingham NG7 2RD, UK; ${ }^{4}$ Medical \\ School, Kunming University of Science \\ and Technology, Kunming, People's \\ Republic of China; ${ }^{5}$ Faculty of \\ Engineering, University of Nottingham, \\ Nottingham NG7 2RD, UK
}

Correspondences: Tracey D Bradshaw Centre for Biomolecular Sciences, School of Pharmacy, University of Nottingham, Nottingham NG7 2RD, UK

Tel +44 II 95 I5033

Email Tracey.Bradshaw@nottingham.ac.uk

Lyudmila Turyanska

Faculty of Engineering, University of

Nottingham, Nottingham NG7 2RD, UK

$\mathrm{Tel}+44$ II5 951515।

Email Lyudmila.Turyanska@nottingham.ac.uk
Introduction: Advancement of novel anticancer drugs into clinical use is frequently halted by their lack of solubility, reduced stability under physiological conditions, and non-specific uptake by normal tissues, causing systemic toxicity. Their progress to use in the clinic could be accelerated by the development of new formulations employing suitable and complementary drug delivery vehicles.

Methods: A robust method for apoferritin (AFt)-encapsulation of antitumour benzothiazoles has been developed for enhanced activity against and drug delivery to benzothiazolesensitive cancers.

Results: More than 70 molecules of benzothiazole 5F 203 were encapsulated per AFt cage. Post-encapsulation, the size and integrity of the protein cages were retained as evidenced by dynamic light scattering. ToF-SIMS depth profiling using an argon cluster beam confirmed 5F 203 exclusively within the AFt cavity. Improved encapsulation of benzothiazole lysyl-amide prodrugs was achieved ( $\sim 130$ molecules of Phortress per AFt cage). Transferrin receptor 1, TfR1, was detected in lysates prepared from most cancer cell lines studied, contributing to enhanced anticancer potency of the AFt-encapsulated benzothiazoles (5F 203, Phortress, GW 610, GW 608-Lys). Nanomolar activity was demonstrated by AFt-formulations in breast, ovarian, renal and gastric carcinoma cell lines, whereas $\mathrm{GI}_{50}>50 \mu \mathrm{M}$ was observed in nontumourigenic MRC-5 fibroblasts. Intracellular 5F 203, a potent aryl hydrocarbon receptor (AhR) ligand, and inducible expression of cytochrome $\mathrm{P}_{450}$ (CYP) 1A1 were detected following exposure of sensitive cells to AFt-5F 203, confirming that the activity of benzothiazoles was not compromised following encapsulation.

Conclusion: Our results show enhanced potency and selectivity of AFt-encapsulated 5F 203 against carcinomas derived from breast, ovarian, renal, colorectal as well as gastric cancer models, and offer realistic prospects for potential refinement of tumour-targeting and treatment, and merit further in vivo investigations.

Keywords: benzothiazole, apoferritin, transferrin receptor, anticancer activity, drug delivery

\section{Introduction}

Development of drug delivery vehicles is of great importance for advancement of novel drugs into the clinic, and could be used to address their limited solubility, stability in physiologically relevant solvents, provide targeted delivery of the drug, hence limiting systemic toxicities. ${ }^{1}$ These disadvantages are often only apparent at later phases in drug development. Nanomedicine has already enabled significant progress in the development of advanced therapeutic agents and further investigations are ongoing to achieve successful translation into the clinic. ${ }^{2-4}$ Several drug delivery 
nano-vehicles have been identified, including ones derived from lipids, ${ }^{5}$ synthetic polymers ${ }^{6,7}$ and proteins. ${ }^{8}$ Of particular interest are protein capsules as they are biocompatible, biodegradable and species-specific, hence they are not expected to accumulate in the body or induce an immune response if species matched. ${ }^{9}$ Of additional benefit is the possibility to genetically modify the protein surface for attachment of targeting molecules. ${ }^{10}$ Proteins from the ferritin family, such as apoferritin (AFt) and Dps have emerged as promising candidates for drug delivery and have been successfully used to encapsulate small molecules and imaging agents. ${ }^{11-13}$ Encapsulation of anticancer therapeutic agents into AFt has attracted considerable attention due to internalisation of AFt-encapsulated cargo via transferrin receptor 1 (TfR1)-mediated endocytosis ${ }^{14,15}$ and cellular recognition of modified AFt by receptors, such as EGFR, which are overexpressed in specific cancers. ${ }^{16}$ Despite promising applications, AFt encapsulation of drugs remains challenging and the procedure requires optimization.

The experimental antitumour agents 2-(4-amino3-methylphenyl)-5-fluorobenzothiazole (5F 203, Figure 1a) and 2-(3,4-dimethoxyphenyl)-5-fluorobenzothiazole (GW610; Supplementary Information Scheme S1) elicit exquisitely potent and selective anticancer activity in certain cancer models via a mechanism distinct from current clinical anticancer therapies. ${ }^{17,18}$ The compounds are potent aryl hydrocarbon receptor (AhR) ligands, and induce their own cytochrome P450 (CYP) 1A1 and 2W1catalyzed metabolism to generate electrophilic species which then form DNA adducts leading to lethal DNA double-strand breaks; this occurs exclusively in sensitive phenotypes. ${ }^{19}$ However, systemic exposure and adverse toxicity in potentially susceptible healthy tissues (e.g. lung, liver) ${ }^{20}$ and the poor water-solubility of $5 \mathrm{~F} 203$ limit its advance into the clinic.

Here we develop a new formulation of 5F 203 addressing its toxicity and solubility. The agent has been encapsulated within horse spleen AFt protein cages. AFt-encapsulation protocols have been systematically investigated to optimize encapsulation efficiency; complementary characterization techniques have been employed to study $\mathrm{AFt}$ integrity and confirm 5F 203 encapsulation. Direct determination of encapsulation of 5F-203 inside the AFt cage was achieved by TOF-SIMs. The antitumour activity of the AFtencapsulated agents was interrogated in breast, ovarian, renal, colorectal, lung and gastric cancers; concurrently, studies were undertaken to verify that the cellular mechanism of action of 5F 203 was not compromised following its encapsulation in AFt nanocages.

\section{Materials and Methods Encapsulation Methods}

Encapsulation of 5F 203 was performed using both the nanoreactor and reassembly routes (Figure S1). In the nanoreactor route, molecules are encapsulated by passive diffusion through 3 and 4 Angstrom channels at the protein junctions in the AFt shell. In the reassembly route, the ability of the AFt cage to disassemble into its subunits and reassemble is used to entrap the cargo. Two triggers were used for reassembly: $\mathrm{pH}$-dependent and urea-induced reassembly. Horse spleen ferritin (Sigma Aldrich) was used to prepare AFt and was used for encapsulation.

The optimized nanoreactor method was used for subsequent encapsulation of Phortress, GW610 and GW 608Lys. The chemical structure of all test agents is shown in Scheme S1.

Characterisation methods: UV-vis spectroscopy: The benzothiazole concentrations were determined by measurement of absorbance at $360,334,325$ and $336 \mathrm{~nm}$ for 5F 203, GW 610, Phortress and GW 608-Lys, respectively, on a Varian Cary50 UV-Vis spectrometer, using a calibration curve $\left(\mathrm{R}^{2}>0.999\right)$ obtained from samples of known benzothiazole concentration. Transmission electron microscopy: For transmission electron microscopy (TEM), the samples were deposited onto graphene oxidecoated copper grid and images were acquired on a JEM2100F, JOEL operated at $200 \mathrm{kV}$. Dynamic Light Scattering (DLS): DLS analyses were carried out at $25^{\circ} \mathrm{C}$ using a Zetasizer Nano spectrometer (Malvern Instruments Ltd) equipped with a $633 \mathrm{~nm}$ laser at a fixed angle of $173^{\circ}$. ToF-SIMs: Time of Flight Secondary Ion Mass Spectrometry (ToF SIMS) analysis was carried out on a ToF-SIMS IV instrument (ION-TOF GmbH, Munster, Germany) equipped with a bismuth liquid metal ion gun and a single-stage reflectron analyser. Bradford assay: The AFt concentration was determined by Bradford assay. Briefly, $10 \mu \mathrm{L}$ of sample was diluted in $90 \mu \mathrm{L}$ of d. $\mathrm{H}_{2} \mathrm{O}$ in a 96 -well microliter plate and 140 $\mu \mathrm{L}$ of Bradford reagent was added. After 5-min incubation, the plate was read at $595 \mathrm{~nm}$ using a Perkin Elmer plate reader. A calibration curve was constructed, using bovine serum albumin (BSA) from 0.1 to $1.0 \mathrm{mg} \mathrm{mL} \mathrm{m}^{-1}$ and used to convert absorbance readings to protein concentrations. 


\section{In vitro Cell Culture Studies}

All cell lines were purchased from the American Type Culture Collection (ATCC) and cultured in RPMI 1640 medium supplemented with $10 \% \mathrm{v} / \mathrm{v}$ foetal bovine serum (FBS) at $37^{\circ} \mathrm{C}$ in an atmosphere of $5 \% \mathrm{CO}_{2}$. Cells were passaged twice weekly to maintain continuous logarithmic growth. In this work, we have used the following human-derived cell lines: non-tumourigenic foetal fibroblast MRC-5; breast cancer cell lines MCF-7, MDA-MB-468, renal cancer cell TK10, ovarian cancer cell IGROV-1, colorectal cancer cells HCT 116, HCC 2998 and KM12; gastric cancer cells MKN-45, NCI-N87, KATO-III, BGC-823 and SGC-7901.

For MTT assays, cells were seeded at a density of $5 \times 10^{3}$ cells per well into 96-well plates and allowed 24 hrs to adhere. Serial dilutions were prepared in medium and added to cells ( $n=4$ per concentration). Viable cells at the time of test agent addition (T0), and following $72 \mathrm{hrs}$ of drug exposure were determined by cell-mediated 3-(4,5-dimethylthiazol-2-yl)-2,5-diphenyltetrazolium bromide (MTT) reduction. MTT was added to each well

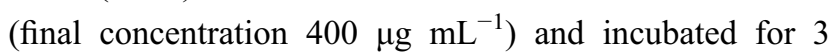
hrs at $37^{\circ} \mathrm{C}$. Well supernatants were aspirated and formazan solubilized with $150 \mu \mathrm{L}$ DMSO. Absorbance was read at $550 \mathrm{~nm}$ using Perkin Elmer Envision plate reader. The $\mathrm{GI}_{50}$ values were determined by interpolation.

For clonogenic assays, 250 cells per well were seeded into 6-well plates and allowed $24 \mathrm{hrs}$ to attach. Test compounds were added at $\mathrm{GI}_{50}$ concentrations. After 24 hrs exposure, the medium was aspirated and cells washed with PBS $(2 \times 1 \mathrm{~mL})$ before incubation in medium $(2 \mathrm{~mL})$ for 7-9 days. Experiments were terminated when colonies $\geq 50$ cells were observed in control wells. Colonies were washed (PBS, $2 \times 1 \mathrm{~mL}$ ), fixed (methanol, $15 \mathrm{mins}$ ), stained ( $0.5 \%$ methylene blue, 15 mins) and counted.

\section{Confocal Microscopy}

Following required treatments, cells were lysed and proteins separated by SDS-PAGE then electroblotted onto PVDF membranes, Membranes were blocked in Tris-buffered saline (TBS) containing 5\% milk and $0.1 \%$ Tween$20(1 \mathrm{hr})$, then incubated with $1^{\circ}$ Abs (CYP 1A1, TfR1; Cell Signaling; $\mathrm{O} / \mathrm{N}, 4^{\circ} \mathrm{C}$ ). Membrane incubation with 20 Abs preceeded ECL detection. Images were examined on a C-DiGit blot scanner (LI-Cor-Biosciences). Cells were seeded at a density of $2 \times 10^{5}$ in wells with coverslips and allowed $24 \mathrm{hrs}$ to attach. Following $24 \mathrm{hrs}$ exposure to the test compound, live images of the cells were taken using a Zeiss LSM 510 fluorescence microscope equipped with a UV laser.

\section{Statistical Analysis}

All experiments were repeated at least three times and results are reported as mean \pm standard deviation (SD). Statistical significance was assessed using ANOVA.

\section{Results and Discussion Development and Optimization of $\mathrm{AFt}$ Encapsulation Method}

Encapsulation of 5F 203 was performed using both nanoreactor and reassembly routes (Figure 1), following the

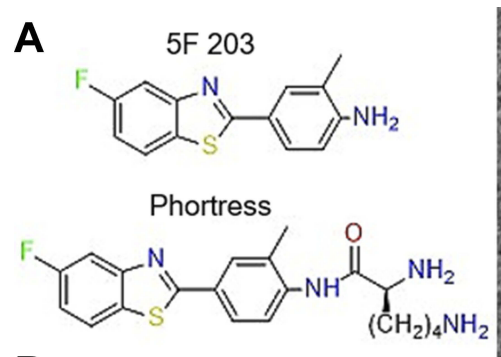

B
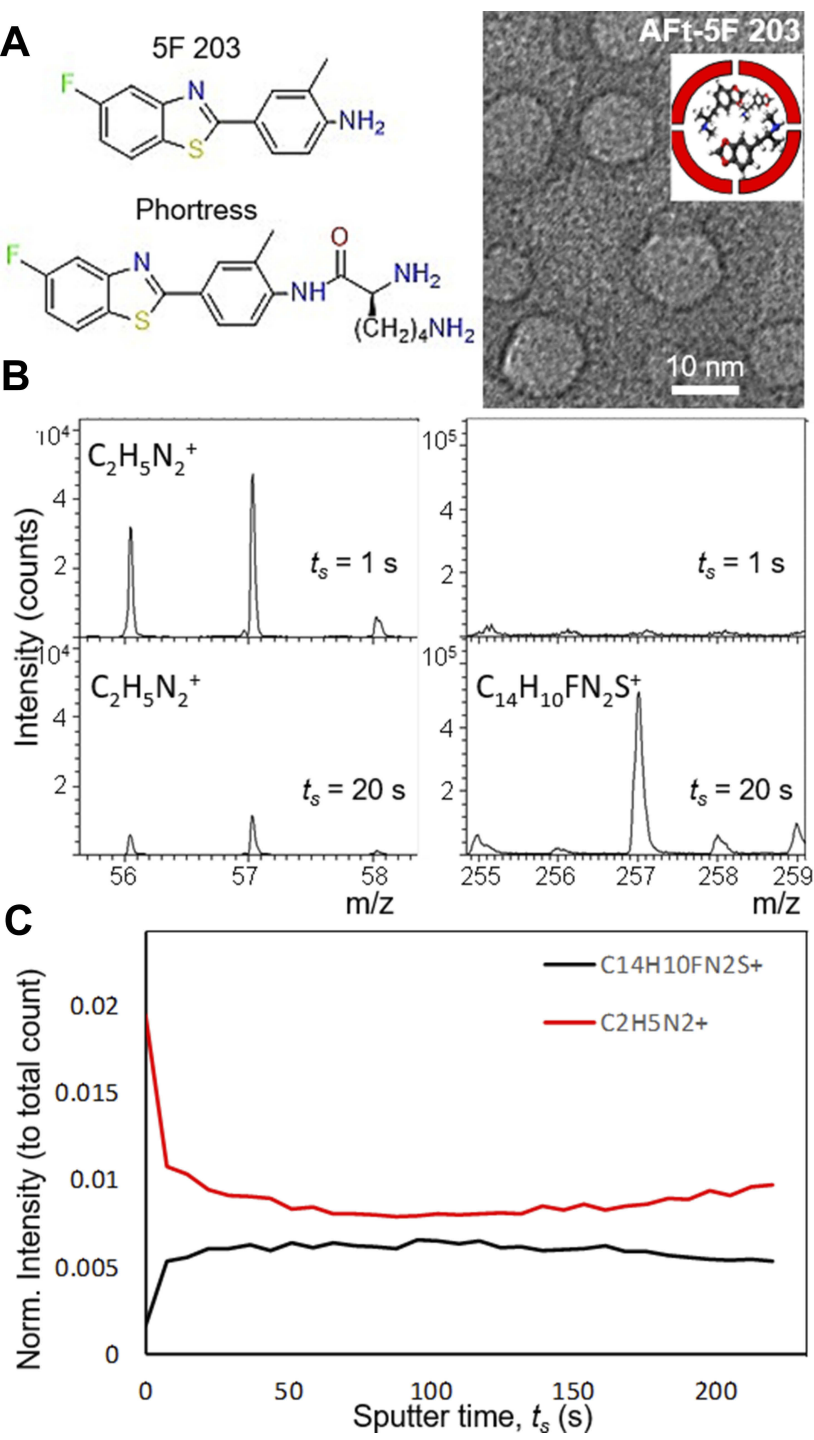

Figure I (A, left) Chemical structure of test agents 5F 203 and Phortress and (right) a cartoon and a representative dark field TEM image of Apoferritinencapsulated 5F 203. (B) TOF SIMs Mass spectra of AFt-5F 203. (C) A summary of intensity change with increasing sputter time. 
modified method developed for encapsulation of nanocrystals. ${ }^{21,22}$ Initially, a ratio of five molecules of $5 \mathrm{~F}$ 203 per AFt cage (24 protein subunits per cage, horse spleen AFt) were mixed together under dialysis (see Experimental section), however significant amounts of precipitate formed. The precipitate was removed and the supernatant was used to assess the concentrations of $5 \mathrm{~F}$ 203 and AFt by UV-vis spectroscopy and Bradford assays, respectively. For both the nanoreactor and reassembly routes, only $\sim 0.5-1.5 \% \quad 5 \mathrm{~F} 203$ and $<1 \%$ AFt was detected.

In the nanoreactor route, the number of 5F 203 molecules was increased to 100 per AFt cage, improving the encapsulation efficiency to $47 \%$; however, the loss of the protein during encapsulation was still significant. The choice of buffer is of great importance for AFt stability and solubility. Hence, sodium acetate buffer ( $\mathrm{pH}$ 5.5) was replaced by TRIS-buffer ( $\mathrm{pH}$ 7.4) which had previously been reported for encapsulation of doxorubicin [10], but this failed to decrease protein precipitation. The use of 4-(2-hydroxyethyl)-1-piperazineethanesulfonic acid (HEPES) buffer and a reduced concentration of AFt (halved to $\sim 1.5 \mathrm{mg}$ $\mathrm{mL}^{-1}$ ) enabled encapsulation without significant loss of protein, with up to $72 \%$ of AFt remaining in solution. Hence, HEPES buffer was used to further increase the number of test agent molecules per AFt cage. Since the aqueous solubility of benzothiazoles is very low, 5F 203 was added in aliquots (equivalent of 100 molecules per AFt cage was added at 30 mins intervals). Using this method, we achieved encapsulation of 71 molecules per AFt cage. Dynamic light scattering (DLS) studies of the resulting solution revealed an average size of $13.1 \pm 1.6 \mathrm{~nm}$, as expected for single AFt cages, confirming that the size and the integrity of the AFt had not been affected by encapsulation of 5F 203. Transmission electron microscopy (TEM) studies confirmed that integrity of the AFt capsule is not affected by the encapsulation. We observed the AFt capsules with an average diameter of $11.6 \pm$ $1.9 \mathrm{~nm}$ (Figure 1A).

\section{Examining Encapsulation Efficiency of the Agent}

In order to investigate whether the encapsulation efficiency could be improved using the reassembly route, two methods were trialed: $\mathrm{pH}$-induced and urea-induced reassembly. For pH-induced reassembly, 5F 203 was added to AFt subunits (disassembly at $\mathrm{pH}=2$ ) and the $\mathrm{pH}$ was raised to $\mathrm{pH} 4.0$ (using $1 \mathrm{M}, \mathrm{NaOH}$ ) and then to 7.4 (by addition of $1 \mathrm{M}$, tris buffer), to gradually reform the $\mathrm{AFt}$ cages. The $\mathrm{AFt}$ remained in solution, but significant loss of test agent was observed (only $1.3 \%$ of test agent encapsulated). To address obstacles posed by agent solubility, we used a glycine/ HEPES buffer and reduced the concentration of $\mathrm{AFt}$ $\left(1.5 \mathrm{mg} \mathrm{mL} L^{-1}\right)$. The reassembly of AFt capsules was initiated by direct addition of base; this was necessary to limit the time that the solution was kept in the $\mathrm{pH} 4.5-6.5$ range, which is close to the isoelectric point of the $\mathrm{AFt}$ subunits and could lead to precipitation. ${ }^{12}$ This method resulted in $>55 \%$ of $\mathrm{AFt}$ remaining in solution and encapsulation of 25 molecules of 5F 203 per AFt cage. However, DLS studies indicated that the reassembly of the AFt capsule under these conditions was altered leading to the formation of larger protein cages (average diameter $20.9 \pm$ $2.8 \mathrm{~nm}$ ). Following filtration, only a small fraction of the samples demonstrated the expected diameter of $12.7 \pm 1.8$ $\mathrm{nm}$. These results could be associated with the formation of nanocages larger than the expected 24-mer, or possible damage to AFt leading to the formation of holes in the AFt surface. ${ }^{23}$ It was hypothesised that disassembly of AFt using the urea method may provide more efficient protein reassembly; ${ }^{24}$ However, the results of encapsulation were similar to those obtained using the $\mathrm{pH}$ method. Since the reassembly routes failed to increase the encapsulation efficiency, the nanoreactor method with gradual addition of the test agent as multiple aliquotes was adopted for all subsequent studies. Encapsulation using the nanoreactor route was performed at $\mathrm{pH} 5.5$. We anticipate no significant leakage of the encapsulated agent during storage $(\mathrm{pH} 7$ and $\mathrm{T}=4^{\circ} \mathrm{C}$ ) as AFt pore size is reduced under these conditions.

To confirm that 5F 203 was encapsulated within the AFt cavity and not bound to the surface, time of flight secondary ion mass spectrometry (ToF-SIMS) was performed (Figure $1 \mathrm{~B}$ and $\mathrm{C}$ ). We observed a series of distinctive peaks corresponding to $\mathrm{AFt}$ at $56-58 \mathrm{~m} / \mathrm{z}$ range and to $5 \mathrm{~F}$ 203 at $255-295 \mathrm{~m} / \mathrm{z}$ range. With increasing sputter time, the intensity of the peaks at $56-58 \mathrm{~m} / \mathrm{z}$ is reduced and accompanied by increased signal at the $5 \mathrm{~F} 203$ range. The peaks of the drug are not visible in the AFt, until the protein shell is removed. We note that the signals corresponding to common contaminants such as $\mathrm{Na}^{+}, \mathrm{K}^{+}$, and PDMS did not reduce with increasing sputter time. Hence, depth profiling using an Argon cluster beam to remove a layer of the sample was applied and revealed 5F 203 peaks exclusively below the AFt surface, within the cavity. These ToF-SIMS results confirm that the drug is encapsulated inside the $\mathrm{AFt}$ 
cavity and provide the first direct examination of the morphology of the protein encapsulated structures.

\section{In vitro Assessment of Anticancer Activity}

We recently reported that conjugation to a lysine moiety significantly enhances the encapsulation of benzothiazole $\mathrm{GW} 610$ in $\mathrm{AFt}$, resulting in a more potent formulation. ${ }^{25}$ Moreover, the lysylamide prodrug of $5 \mathrm{~F}$ 203 (Phortress) has advanced to clinical evaluation because of its selective potent antitumour activity in vitro and in vivo against breast and ovarian cancer models, unique mode of action and favourable pharmacokinetic properties. ${ }^{20,26}$ Therefore, Phortress, was encapsulated within AFt. Promising encapsulation results were achieved with 130 molecules of Phortress per AFt cage, with a corresponding encapsulation efficiency (EE) of $8 \%$ and drug loading of $10 \%$. Phortress encapsulation efficiency was slightly higher compared to 5F 203, likely a consequence of the difference in polarity and lipophilicity of the test agents (Supplementary Information SI1, Scheme S1 and Figure S2).
The rate at which test agents are released from a delivery capsule could significantly impact its therapeutic properties. Hence, release rates were studied at physiologically relevant $\mathrm{pH}$ values of 7.4 and 6.5 . It has been reported that a lower $\mathrm{pH}$ of $\sim 6.5$ is normally associated with tumour microenvironments. ${ }^{27}$ Figure 2 shows that the release of $5 \mathrm{~F}$ 203 occurs steadily over $24 \mathrm{hrs}$ with $100 \%$ release observed $<24 \mathrm{hrs}$ at both $\mathrm{pH} 6.5$ and 7.4 at $37^{\circ} \mathrm{C}$. Phortress was readily released from the AFt core with $100 \%$ release observed within $9 \mathrm{hrs}$. This observation is in contrast to the reported release of doxorubicin from $\mathrm{AFt}^{24}$ where no significant release was observed at $\mathrm{pH} 7.4$ after $60 \mathrm{hrs}$. This difference may be attributed to the combination of the size and polarity of the test agents, i.e. doxorubicin is a larger $\left(544 \mathrm{~g} \mathrm{~mol}^{-1}\right)$, more polar molecule than 5F 203 (258 $\mathrm{g} \mathrm{mol}^{-1}$ ) and Phortress (386 $\left.\mathrm{g} \mathrm{mol}^{-1}\right)$, hence its diffusion out from the lumen/core through the AFt pores (3-4 $\AA$ diameter) is unlikely at near neutral $\mathrm{pH}$.

To understand the effects of encapsulation on the in vitro antitumour activity of the benzothiazoles, both non-encapsulated (naked) and encapsulated forms of $5 \mathrm{~F}$ 203 and Phortress were tested against a range of cell lines

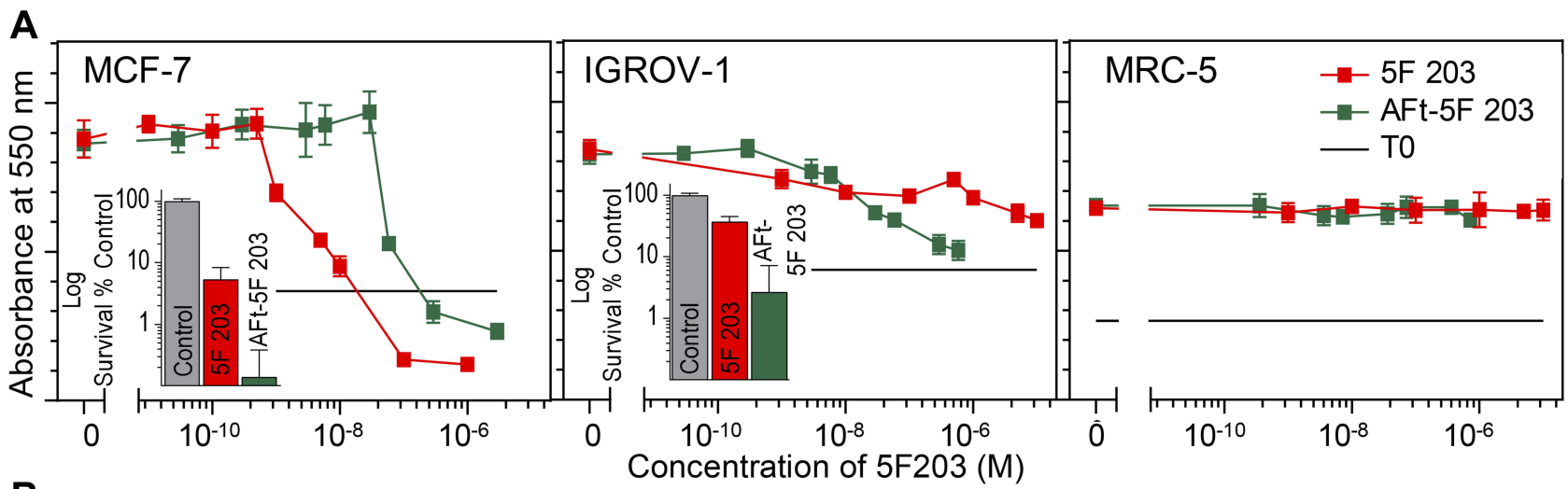

B Concentration of 5F203 (M)

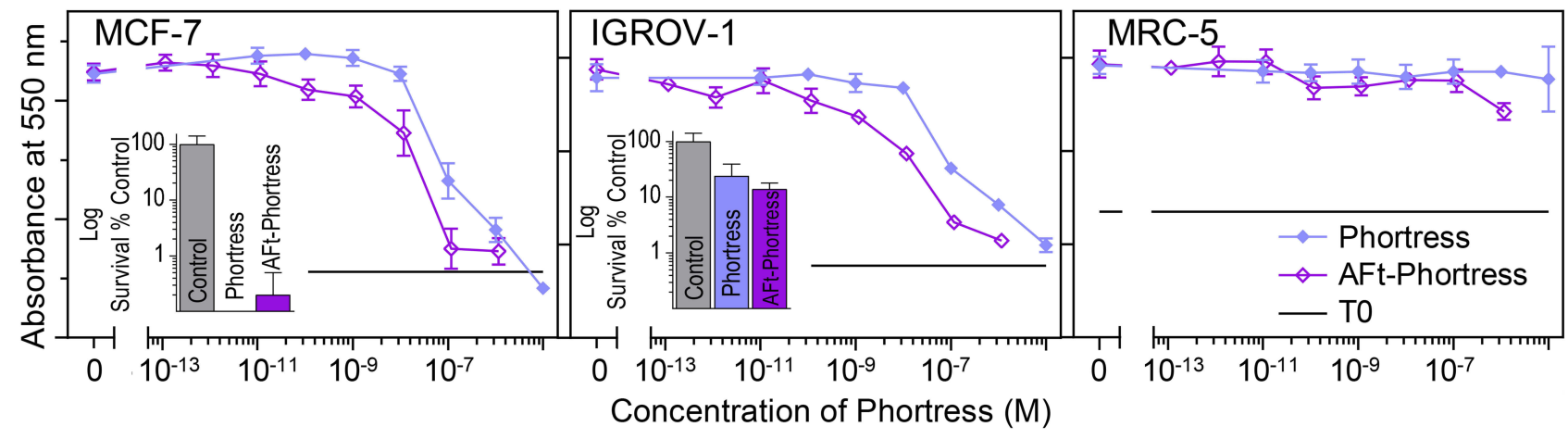

Figure 2 MTT assay (72 hrs exposure) dose-response curves of (A) 5F 203 and AFt-5F 203 and (B) Phortress and AFt-Phortress in MCF-7, IGROV-I and MRC-5 cell lines. Data points are mean $\pm S D, n=4$ in one representative trial, number of independent trials $=3$. Insets: Clonogenic assay displaying survival fractions following 24 exposure treated at $\mathrm{Gl}_{50}$ values in corresponding cell lines. Data points are mean $\pm \mathrm{SD}$, taken from 3 independent trials where $\mathrm{n}=4$ per trial. 
Table I GI 50 Values Calculated from MTT Assay $(72 \mathrm{Hrs}$ ) of Naked and Encapsulated Forms of $5 \mathrm{~F} 203$ and Phortress. Gl 50 ls Mean \pm SD from Three Independent Trials, Where $N=4$

\begin{tabular}{|c|c|c|c|c|c|}
\hline & \multirow[t]{2}{*}{ Cells Line } & \multicolumn{4}{|l|}{ Test Agent } \\
\hline & & 5F 203 & AFt-5F 203 & Phortress & AFt- Phortress \\
\hline $\mathrm{Gl}_{50} \pm \mathrm{SD}(\mu \mathrm{M})$ & $\begin{array}{l}\text { MCF-7 } \\
\text { MDA-468 } \\
\text { TK-10 } \\
\text { IGROV-I } \\
\text { HCT-II6 } \\
\text { MRC-5 }\end{array}$ & $\begin{array}{l}0.005 \pm 0.0006 \\
0.014 \pm 0.007 \\
0.11 \pm 0.09 \\
12.8 \pm 10.2 \\
>50 \\
>50\end{array}$ & $\begin{array}{l}0.033 \pm 0.009 \\
0.008 \pm 0.008 \\
0.028 \pm 0.004 \\
0.039 \pm 0.011 \\
>0.61 \\
>0.61\end{array}$ & $\begin{array}{l}0.085 \pm 0.017 \\
0.11 \pm 0.013 \\
6.3 \pm 2.9 \\
0.17 \pm 0.070 \\
>50 \\
>50\end{array}$ & $\begin{array}{l}0.063 \pm 0.030 \\
0.11 \pm 0.035 \\
0.098 \pm 0.008 \\
0.058 \pm 0.022 \\
0.14 \pm 0.059 \\
>2.5\end{array}$ \\
\hline
\end{tabular}

via MTT assays following $72 \mathrm{hrs}$ exposure of cells to test agent. The cell lines selected for study included: MCF-7, MDA-MB-468 breast, TK10 renal, IGROV-1 ovarian, HCT 116 colorectal (CRC) cancer cell lines and nontumourigenic MRC-5 fibroblasts. The results of the MTT tests are summarised in Table 1 and representative doseresponse curves are illustrated in Figure 2 and SI Figures $\underline{\mathrm{S} 3}$ and $\underline{\mathrm{S}} 4$. In the majority of sensitive cell lines, the encapsulated benzothiazole is more potent than the naked agent. The increase in potency for example in TK10 renal and IGROV-1 ovarian cell lines, respectively, is $\sim 4 \times$ and $>300 \times$ for AFt-5F 203, and $>60 \times$ and $3 \times$ for AFtPhortress. In the benzothiazole-insensitive cell line HCT116 and in non-tumorigenic fibroblasts (MRC-5), both 5F 203 and Phortress were inactive $\left(\mathrm{GI}_{50}\right.$ values $\left.>50 \mu \mathrm{M}\right)$. No growth inhibition was encountered following AFt-
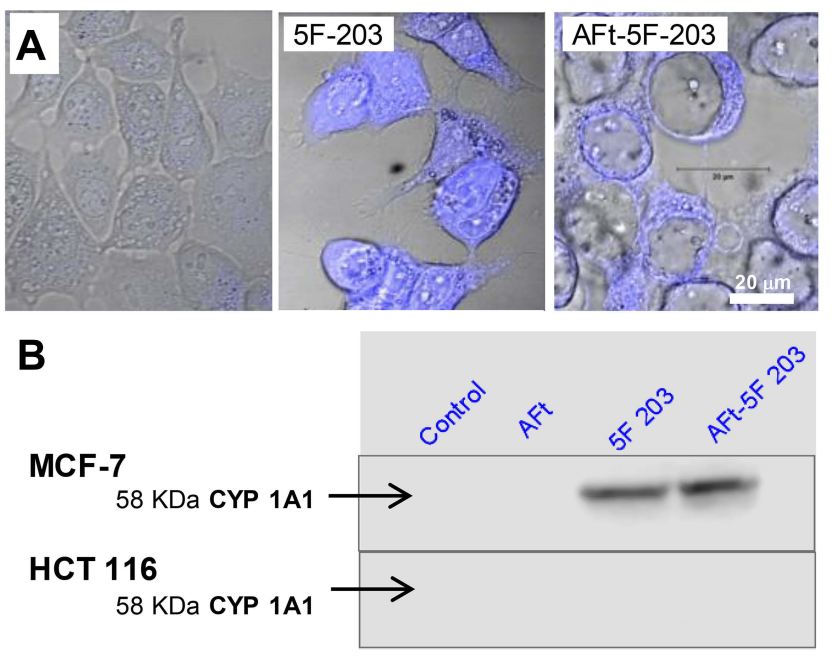

Figure 3 (A) Confocal microscopy images of MCF-7 cells and following $24 \mathrm{hrs}$ exposure of cells to AFt, 5F 203 alone and AFt-5F-203 prepared via nanoreactor route. (B) Selective induction of CYPIAI protein in lysates of sensitive MCF-7 cells only following exposure to naked and encapsulated agent (24 hrs; I $\mu M$ 5F 203); lysates prepared from HCT 116 cells express neither inducible nor constitutive CYPIAI. encapsulation of either agent in MRC-5 cells (Table 1) confirming that cancer cell-selectivity is preserved following encapsulations. Surprisingly, HCT 116 CRC cells (which do not express inducible CYP1A1; SI Figure 3) did demonstrate sensitivity to AFt-Phortress (Table 1 and Supplementary Information SI2 and Figures S3 and S4). Similar to the naked agent, AFt-5F 203 was more active than AFt-Phortress in all sensitive cell lines tested, exemplified by increased potency (with correspondingly reduced $\mathrm{GI}_{50}$ values) by factors of $\sim 1.5 \times$ in IGROV-1, and $3.5 \times$ in $\mathrm{TK}-10$. However, if $\mathrm{GI}_{50}$ values in relation to AFt concentration are considered, AFt-Phortress is more potent (than AFt-5F 203) in the sensitive cell lines tested, increasing potency by a factor ranging from $\sim 3 \times$ for MCF7 and up to $\sim 22 \times$ for TK-10. The in vitro antitumour activity observed in the MTT assays was corroborated by clonogenic assays (Figure 2, SI S3 and S4). Clonogenic survival was inhibited in all sensitive cell lines tested and AFt-encapsulated benzothiazoles were either equally, or more potent than free drug. Thus, not only is the enhanced potency of encapsulated benzothiazoles confirmed, but importantly, clonal survival of benzothiazole-sensitive cancer cells is inhibited following brief exposure of cells to AFt-5F 203 and AFt-Phortress. AFt alone did not cause growth inhibition or toxicity in either the MTT or clonogenic assays (up to $1 \mathrm{mg} \mathrm{mL} \mathrm{m}^{-1}$ ), confirming the biocompatibility of this protein and its potential for drug delivery applications.

We envisage that the enhanced toxicity of the encapsulated agents is a consequence of cellular recognition of $\mathrm{AFt}$ by the transferrin receptor (TfR1) and receptormediated endocytosis. ${ }^{28}$ Membrane TfR1 expression is markedly upregulated in many cancers including colon and breast. ${ }^{14,16}$ To examine this hypothesis, we assessed TfR1 expression in the studied cell lines. The results confirm TfR1 expression in lysates of most cancer cells, 
revealing an order of TfR1 expression in benzothiazolesensitive carcinoma cell lines as follows: KM-12 > MCF-7 $>$ TK-10 > HCC-2998 > IGROV-1 > MDA-MB-468 (Supplementary Information SI2 and Figures S5 and S6). Insensitive MRC-5 fibroblasts showed undetectable levels of TfR1 expression, whereas TfR1 expression was evident in HCT 116 lysates. These results are consistent with observed differences in $\mathrm{GI}_{50}$ values following benzothiazole encapsulation. For example, the highest expression of TfR1 was seen in KM-12 cells; as reported, enhanced potency of AFt-encapsulated benzothiazoles GW 610 and GW608-Lys, by $\sim 50$ - and $>750$-fold, respectively, was seen in this cell line. ${ }^{25}$ Moderate expression of TfR 1 in TK-10 (and HCC-2998) cells corresponded to $\sim 4$-fold and 64-fold enhanced activity of AFT-encapsulated 5F 203 and Phortress in TK10 cells. No TfR1 expression was detected in MDA-MB-468 cells, and no difference was observed in $\mathrm{GI}_{50}$ values of naked or encapsulated Phortress $(0.11 \mu \mathrm{M})$.

In the benzothiazole-insensitive HCT 116 cell line, growth inhibition was observed following exposure of cells to AFt-Phortress, facilitated (we speculate) by TfR1mediated endocytosis of the AFt formulation. However, direct correlation between TfR1 expression and $\mathrm{GI}_{50}$ values was not observed in MCF7 and IGROV-1 cell lines. There is strong TfR1 expression in MCF-7 cells; however, there was no enhanced potency of the encapsulated benzothiazoles; in IGROV-1 cells, there is minimal TfR1 expression, however dramatically increased potency following encapsulation of 5F 203 was observed. Abundant cytosolic AhR expression in MCF-7, IGROV-1 (and MDA-468) cells promotes rapid depletion of 5F 203 from nutrient medium, sequestration and ligand-receptor binding. ${ }^{29}$ Un-encapsulated (naked) benzothiazoles rely on passive diffusion and their hydrophobic nature to cross the cell membrane and enter cells. Cytosolic AhR expression in cancer cells correlates with rapid sequestration of antitumour benzothiazoles such as 5F 203. These observations correlate with CYP1A1 induction and generation of DNA adducts over the initial $24 \mathrm{hrs}$ exposure of MCF-7 and IGROV-1 cells to 5F 203, or Phortress. ${ }^{30,31}$

\section{Cellular Uptake of AFt-Encapsulated Agents}

Confocal microscopy was performed following exposure of MCF-7 cells to naked and AFt-encapsulated 5F 203 (Figure 3). Additionally, lysates were prepared from MCF-
7 and HCT 116 cells exposed to naked and AFtencapsulated 5F 203 and induction of CYP1A1 protein expression was examined to investigate AhR-signal transduction activation by 5F 203 (a potent AhR ligand). ${ }^{32}$ Intracellular 5F 203 was clearly observed in MCF-7 cells exposed to both naked and AFt-encapsulated 5F 203 (Figure 3A). Moreover, clear expression of CYP1A1 protein exclusively in benzothiazole-sensitive $\mathrm{MCF}-7$ cells exposed to naked and AFt-encapsulated 5F 203 provided evidence of AhR signal transduction. AFt alone did not induce CYP1A1, and no CYP1A1 protein was detected in lysates of insensitive HCT 116 cells exposed to 5F 203 or AFt-5F 203 (Figure 3B). As inferred, the surprising activity observed following exposure of HCT 116 cells to AFtPhortress maybe a consequence of its TfR1-mediated cellular internalization. We conclude that CYP1A1-inducibility by antitumour benzothiazoles is not compromised following encapsulation in $\mathrm{AFt}$ protein nanocages.

\section{Studies in Gastric Cell Lines}

Encapsulation of benzothiazoles into the AFt cavity offers a number of advantages compared to other delivery vehicles, such as enhanced solubility, bioavailability and selective uptake. Passive tumour-targeting to the tumour microenvironment can be achieved via EPR, and active tumour targeting via TfR1-mediated internalization (and cytosolic AhR-mediated sequestration). Only a subset of cancers demonstrates sensitivity to antitumour benzothiazoles with $\geq 4$ log-fold selectivity between sensitive and

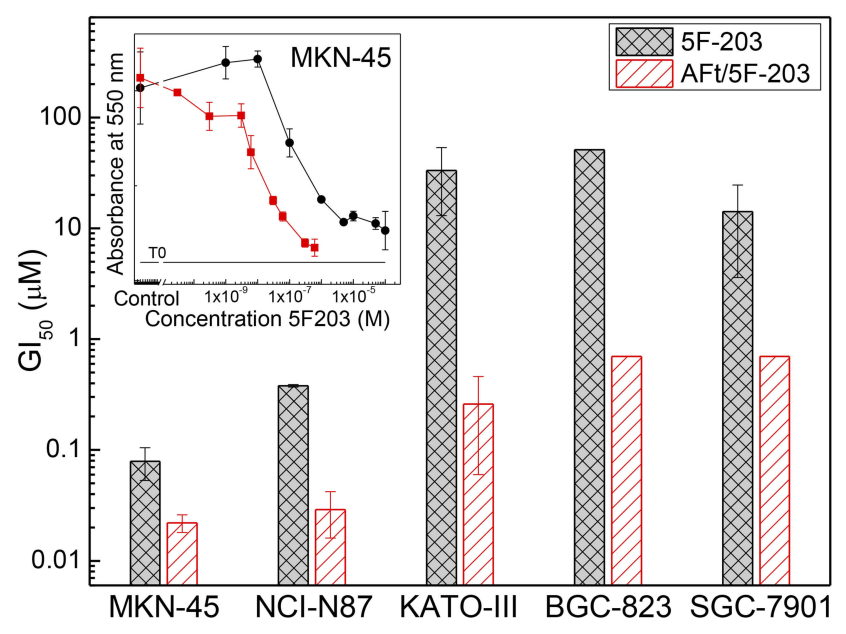

Figure 4 Histograms of $\mathrm{Gl}_{50}$ values for all gastric cell lines treated with $5 \mathrm{~F} 203$ and AFt-5F 203; means \pm SEM from 3 independent trials; $n=4$ per trial. (Inset) Representative dose-response profiles following exposure of gastric cell line MKN-45 to 5F 203 and AFt-5F 203. MTT assays were performed after $72 \mathrm{hrs}$ treatments. 
Table 2 Summary of $\mathrm{Gl}_{50}$ Values Calculated from MTT Assay $(72 \mathrm{Hrs})$ in Gastric Cell Lines for All Test Agents. GI 50 ls Mean \pm SD from Three Independent Trials, Where $\mathrm{N}=4$

\begin{tabular}{|c|c|c|c|c|c|}
\hline \multirow[t]{3}{*}{ Test Agent } & \multicolumn{5}{|c|}{$\mathrm{GI}_{50} \pm \mathrm{SD}(\mu \mathrm{M})$} \\
\hline & \multicolumn{5}{|l|}{ Cell Line } \\
\hline & MKN-45 & NCl-N87 & KATO-III & BGC-823 & SGC-790 I \\
\hline $5 F 203$ & $0.079 \pm 0.026$ & 0.38 & $33.3 \pm 20.9$ & $>51$ & $14.1 \pm 18.5$ \\
\hline AFt/5F 203 & $0.011 \pm 0.004$ & $0.029 \pm 0.013$ & $0.26 \pm 0.2$ & $>0.7$ & $>0.7$ \\
\hline GW610 & $0.43 \pm 0.37$ & $0.4 I \pm 0.34$ & $7.7 \pm 1.1$ & $18.6 \pm|4|$. & $35.1 \pm 8.6$ \\
\hline AFt-GW610 & $0.036 \pm 0.032$ & $0.48 \pm 0.34$ & $0.42 \pm 0.33$ & $1.4 \pm 0.5$ & $>1.8$ \\
\hline GW608Lys & $22.1 \pm 16.8$ & 38.1 & $41.7 \pm 21.4$ & $>50$ & $25.9 \pm 22.5$ \\
\hline AFt/GW608Lys & $0.21 \pm 0.13$ & 0.59 & $>3.5$ & $>3.5$ & $>3.5$ \\
\hline
\end{tabular}

inherently resistant phenotypes. ${ }^{33-36}$ Sensitive tumour types can be identified through ex vivo examination of activity and pharmacodynamic (PD) biomarkers of sensitivity (AhR, DNA adducts). ${ }^{37}$

An additional important benefit of AFt encapsulation, as alluded to in ref. [27], is the sensitivity of the protein capsule to $\mathrm{pH}$, which could offer drug delivery and treatment advantage for gastric cancer. The AFt cage would disassemble in this highly acidic environment releasing its cargo, in this case a potent $\mathrm{AhR}$ ligand, locally, at the tumour site. AhR is expressed by gastric cancer cells and plays a role in gastric carcinogenesis. $^{38,39}$ Moreover, CYP1A1 mRNA and protein expression are inducible in gastric cancer, and CYP 2W1 protein, embryonically expressed in gastrointestinal tissues is highly expressed in gastric cancer. ${ }^{40}$

Our studies in gastric cancer models further validated the selective activity in vitro and efficacy in vivo of $5 \mathrm{~F}$ 203, revealing correlation in this cancer phenotype between benzothiazole activity and CYP 1A1 induction/ CYP2W1 expression. ${ }^{41}$ In our preliminary studies, 10 fold enhanced potency was observed for AFt-encapsulated compared to naked 5F-203 in NCI-N87 cancer cells $\left(\mathrm{GI}_{50}\right.$ values of $0.04 \mu \mathrm{M}$ and $0.38 \mu \mathrm{M}$, respectively, were obtained); 7-fold increased activity was seen in MKN45 cancer cells following 5F 203 AFt-encapsulation $\left(\mathrm{GI}_{50}\right.$ values: 5F 203, $0.011 \mu \mathrm{M}$; AFt-5F 203, $0.079 \mu \mathrm{M})$. In KATO-III cells, $\mathrm{GI}_{50}$ values of $33.3 \mu \mathrm{M}(5 \mathrm{~F} 203)$ and $0.26 \mu \mathrm{M}$ (AFt-5F 203) reflect $>100$-fold enhanced potency following AFt-encapsulation (Figure 4A and Table 2). Further enhancement of the activity of observed following AFt-encapsulation of benzothiazoles GW 610 and GW608-Lys $\quad(\sim 180$ and $\sim 380$ molecules/AFt cage, respectively), ${ }^{25}$ where up to 100 -fold reduction in $\mathrm{GI}_{50}$ values was observed for encapsulated agents in the MKN-45 gastric cell line (Figure 4B and C and Table 2).
We envisage that potency may be further enhanced in vivo where agents will be exposed to $\mathrm{pH} \sim 2$. These results demonstrate a significant advantage of the AFt delivery capsule and merit further assessment in vivo.

\section{Conclusions}

In conclusion, we have developed and optimized a robust biocompatible, formulation for antitumour benzothiazoles that involves encapsulation within AFt protein cages for selective treatment of benzothiazole-sensitive cancer phenotypes. Improved encapsulation has been demonstrated for lysylamide prodrugs Phortress and GW 608-Lys compared to parent 5F 203 and GW 610, respectively; enhanced in vitro antitumour activity of AFt-encapsulated formulations compared to naked 5F 203, Phortress, GW 610 and GW 608-Lys has been encountered; finally, potency against carcinomas derived from breast, ovarian, renal, colorectal as well as gastric cancer models, for which cargo-release at low $\mathrm{pH}$ is pertinent, has been demonstrated. Our results herald exciting prospects for potential refinement of tumour-targeting, imaging (e.g. fluorescence of 5F 203 itself or ${ }^{18}$ F-labelled $5 \mathrm{~F} 203$ ) and treatment, and merit further in vivo investigations.

\section{Acknowledgments}

The authors acknowledge support from the Engineering and Physical Sciences Research Council [grant number EP/L01646X], the CDT in Advanced Therapeutics and Nanomedicine, University of Nottingham, and the EPSRC funded MS service. The authors acknowledge access to the facilities at the Nanoscale and Microscale Research Centre (nmRC), and useful discussions and assistance with TEM from Dr. Michael W Fay. This is part 37 in the series "Antitumour Benzothiazoles". 


\section{Author Contributions}

All authors have made substantial contributions to conception and design of the study, to data acquisition, analysis and interpretation, and towards drafting and critically revising the paper, gave final approval of the version to be published, and agreed to be accountable for all aspects of the work. Major individual contributions are listed as follows. AFB and MLC performed encapsulation experiments, AFB optimized encapsulation procedure, characterized the material and has done in vitro studies. DS provided expertise and performed ToF SIMS measurements. JZ contributed to studies in gastric cell lines. AFB, GW, NRT, LT and TDB conceptualized and designed the project with contribution from all co-authors. AFB, LT and TDB co-wrote the manuscript.

\section{Disclosure}

The authors report no conflicts of interest in this work.

\section{References}

1. Hait WN, Lebowitz PF. Moving upstream in anticancer drug development. Nat Rev. 2019;18(3):159-160. doi:10.1038/d41573018-00006-3

2. Coty J-B, Vauthier C. Characterization of nanomedicines: a reflection on a field under construction needed for clinical translation success. J Control Release. 2019;275(10):254-268. doi:10.1016/j.jconrel.20 18.02.013

3. Aleksandrowicz R, Taciak B, Krol M. Drug delivery systems improving chemical and physical properties of anticancer drugs. $J$ Physiol Pharmacol. 2017;68(2):165-174.

4. Hare JI, Lammers T, Ashford MB, Puri S, Storm G, Barry ST. Challenges and strategies in anti-cancer nanomedicine development: an industry perspective. Adv Drug Deliv Rev. 2017;108:25-38. doi:10.1016/j.addr.2016.04.025

5. Moro M, Di Paolo D, Milione $\mathrm{M}$, et al. Coated cationic lipid-nanoparticles entrapping miR-660 inhibit tumor growth in patient-derived xenografts lung cancer models. $J$ Control Release. 2019;308:44-56. doi:10.1016/j.jconrel.2019.07.006

6. Crecente-Campo J, Guerra-Varela J, Peleteiro M, et al. The size and composition of polymeric nanocapsules dictate their interaction with macrophages and biodistribution in zebrafish. $J$ Control Release. 2019;308:98-108. doi:10.1016/j.jconrel.2019.07.011

7. Zhou Q, Li Y, Zhu Y, et al. Co-delivery nanoparticle to overcome metastasis promoted by insufficient chemotherapy. J Control Release. 2018;275:67-77. doi:10.1016/j.jconrel.2018.02.026

8. Belletti D, Pederzoli F, Forni F, Vandelli MA, Tosi G, Ruozi B. Protein cage nanostructure as drug delivery system: magnifying glass on apoferritin. Expert Opin Drug Deliv. 2017;14(7):825-840. doi:10.1080/17425247.2017.1243528

9. Pisal DS, Kosloski MP, Balu-Iyer SV. Delivery of therapeutic proteins. J Pharm Sci. 2010;99(6):2557-2575. doi:10.1002/jps.22054

10. Bhaskar S, Lim S. Engineering protein nanocages as carriers for biomedical applications. NPG Asia Mater. 2017;9:e371(1-18). doi:10.1038/am.2016.128

11. Tosi G, Belletti D, Pederzoli F, Ruozi B. Apoferritin nanocage as drug reservoir: is it a reliable drug delivery system? Expert Opin Drug Deliv. 2016;13(10):1341-1343. doi:10.1080/17425247.2016.1224848
12. Truffi M, Fiandra L, Sorrentino L, Monieri M, Corsi F, Mazzucchelli S. Ferritin nanocages: a biological platform for drug delivery, imaging and theranostics in cancer. Pharmacol Res. 2016;107:57-65. doi:10.1016/j.phrs.2016.03.002

13. Al-Ani AW, Zhang L, Ferreira L, Turyanska L, Bradshaw TD, Thomas NR. Listeria innocua Dps as a nanoplatform for bioluminescence based photodynamic therapy utilizing gaussia princeps luciferase and zinc protoporphyrin IX. Nanomedicine: NBM. 2019;20:102005 (1-10).

14. Daniels TR, Bernabeu E, Rodriguez JA, et al. The transferrin receptor and the targeted delivery of therapeutic agents against cancer. Biochim Biophys Acta. 2012;1820(3):291-317. doi:10.1016/j. bbagen.2011.07.016

15. Shen Y, Li X, Dong D, Zhang B, Xue Y, Shang P. Transferrin receptor 1 in cancer: a new sight for cancer therapy. Am J Cancer Res. 2018;8(6):916-931.

16. Nicholson RI, Gee JMW, Harper ME. EGFR and cancer prognosis. Eur J Can. 2001;37(4):9-15. doi:10.1016/S0959-8049(01)00231-3

17. Bradshaw TD, Wrigley S, Shi D-F, Schultz RJ, Paull KD, Stevens MFG. 2-(4-Aminophenyl)benzothiazoles: novel agents with selective profiles of in vitro and in vivo activity. $\mathrm{Br} J$ Cancer. 1998;77(5):745-752. doi:10.1038/bjc.1998.122

18. Tan BS, Tiong KH, Muruhadas A, et al. CYP2S1 and CYP2W1 mediate 2-(3,4-dimethoxyphenyl)-5-fluorobenzothiazole ( $\mathrm{GW} \mathrm{610;}$ NSC 721648) sensitivity in breast and colorectal cancer cells. Mol Cancer Ther. 2011;10(10):1982-1992. doi:10.1158/1535-7163.MCT11-0391

19. Stone EL, Citossi F, Singh R, et al. Antitumour benzothiazoles 32: DNA adducts and double strand breaks correlate with activity; synthesis of 5F 203 hydrogels for local delivery. Bioorg Med Chem. 2015;23(21):6891-6899. doi:10.1016/j.bmc.2015.09.052

20. Bradshaw TD, Wren JE, Bruce M, et al. Preclinical toxicokinetic evaluation of phortress (2-(4-amino-3-methylphenyl)-5-fluorobenzothiazole lysylamide dihydrochloride) in two rodent species. Pharmacology. 2009;83(2):99-109. doi:10.1159/000183846

21. Hennequin B, Turyanska L, Ben T, et al. Aqueous near-infrared fluorescent composites based on apoferritin-encapsulated $\mathrm{PbS}$ quantum dots. Adv Mater. 2008;20(19):3592-3596. doi:10.1002/adma. v20:19

22. Bradshaw TD, Junor M, Patane A, et al. Apoferritin-encapsulated $\mathrm{PbS}$ quantum dots significantly inhibit growth of colorectal carcinoma cells. J Mat Chem B. 2013;1(45):6254-6260. doi:10.1039/ c3tb21197e

23. Liang M, Fan K, Zhou M, et al. H-ferritin-nanocaged doxorubicin nanoparticles specifically target and kill tumors with a single-dose injection. Proc Natl Acad Sci USA. 2014;111(41):14900-14905. doi:10.1073/pnas.1407808111

24. Wang Z, Gao H, Zhang Y, Liu G, Niu G, Chen X. Functional ferritin nanoparticles for biomedical applications. Front Chem Sci Eng. 2017;11(4):633-646. doi:10.1007/s11705-017-1620-8

25. Breen A, Wells G, Turyanska L, Bradshaw TD. Development of novel apoferritin formulations for antitumour benzothiazoles. Cancer Rep. 2019;e1155(1-7). doi:10.1002/cnr2.1155

26. Bradshaw TD, Fichtner I, Bibby MJ, et al. Preclinical evaluation of amino acid prodrugs of novel antitumour 2-(4-amino-3-methylphenyl)benzothiazoles. Mol Can Ther. 2002;1:239-246.

27. Feng L, Dong Z, Tao D, Zhang Y, Liu Z. The acidic microenvironment: a target for smart cancer nano-theranostics. Natl Sci Rev. 2018;5:269-286. doi:10.1093/nsr/nwx062

28. Li L, Fang CJ, Ryan JC, et al. Binding and uptake of H-ferritin are mediated by human transferrin receptor-1. Proc Natl Acad Sci USA. 2010;107(8):3505-3510. doi:10.1073/pnas.0913192107

29. Kashiyama E, Hutchinson I, Chua M-S, et al. Antitumor benzothiazoles. 8.1 synthesis, metabolic formation, and biological properties of the $\mathrm{C}$ - and N-oxidation products of antitumor 2-(4-aminophenyl)benzothiazoles3. J Med Chem. 1999;42(20):4172-4184. 
30. Bradshaw TD, Chua M-S, Browne HL, Trapani V, Sausville EA, Stevens MFG. In vitro evaluation of amino acid prodrugs of novel antitumour 2-(4-amino-3-methylphenyl)benzothiazoles. $\mathrm{Br} \mathrm{J}$ Cancer. 2001;86(8):1348-1354.

31. Hose CD, Hollingshead M, Sausville EA, Monks A. Induction of CYP1A1 in tumor cells by the antitumor agent 2-[4-amino-3-methylphenyl]-5-fluoro-benzothiazole: a potential surrogate marker for patient sensitivity. Mol Cancer Ther. 2003;2(12):1265-1272.

32. Bazzi R, Rowlands C, Bradshaw TD, Stevens MFG, Bell D. 2-(4-Amino3-methylphenyl)-5-fluorobenzothiazole is a ligand and shows species-specific partial agonism of the aryl hydrocarbon receptor. Toxico. Appl Pharmaco. 2009;237(1):102-110. doi:10.1016/j.taap.2009.02.015

33. Hutchinson I, Chua M-S, Browne HL, et al. The synthesis and in vitro biological activity of fluorinated 2-(4-aminophenyl)benzothiazoles. $J \mathrm{Med}$ Chem. 2001;44(9):1446-1455. doi:10.1021/jm001104n

34. Shi D-F, Bradshaw TD, Wrigley S, et al. Antitumor benzothiazoles 3. Synthesis of 2-(4-aminophenyl)benzothiazoles and evaluation of their activities against breast cancer cell lines in vitro and in vivo. $J \mathrm{Med}$ Chem. 1996;39(17):3375-3384. doi:10.1021/jm9600959

35. Bradshaw TD, Chua M-S, Browne HL, Trapani V, Sausville EA, Stevens MFG. In vitro evaluation of amino acid prodrugs of novel 2-(4-amino-3-methylphenyl)benzothiazoles. Br J Cancer. 2002;86 (8):1348-1354. doi:10.1038/sj.bjc.6600225
36. Bradshaw TD, Shi D-F, Schultz RJ, et al. Influence of 2-(4-aminophenyl)benzothiazoles on growth of human ovarian carcinoma cell lines in vitro and in vivo. Br J Cancer. 1998;78 (4):421-429. doi:10.1038/bjc. 1998.510

37. Callero MA, Luzzani GA, De Dios DO, Bradshaw TD, Loaiza-Perez AI. Biomarkers of sensitivity to potent and selective antitumor 2-(4-amino3-methylphenyl)-5-fluorobenzothiazole (5F 203) in ovarian cancer. $J$ Cell Biochem. 2013;114(10):2392-2404. doi:10.1002/jcb.24589

38. Andersson P, McGuire J, Rubio C, et al. A constitutively active dioxin/ aryl hydrocarbon receptor induced stomach tumors. Proc Natl Acad Sci USA. 2002;99(15):9990-9995. doi:10.1073/pnas.152706299

39. Peng TL, Chen J, Mao W, Song X, Chen M-H. Aryl hydrocarbon receptor pathway activation enhances gastric cancer cell invasiveness likely through a c-Jun-dependent induction of matrix metalloproteinase-9. BMC Cell Biol. 2009;10:27. doi:10.1186/1471-2121-10-27

40. Zhao Y, Wan D, Yang J, Hammock BD, Ortiz de Montallano P. Catalytic activities of tumour-specific human cytochrome P450 CYP2W1 towards endogenous substrates. DMD. 2016;44(5): 771-780. doi:10.1124/dmd.116.069633

41. Wang Y, Liu Y, Tang T, et al. The antitumor activity of 2-(4-Amino3-methylphenyl)-5-fluorobenzothiazole (5F 203) in human gastric cancer models is mediated by arylhydrocarbon receptor (AhR) signalling. J Cellulat and Molecular Medicine. In press 2019.
International Journal of Nanomedicine

\section{Publish your work in this journal}

The International Journal of Nanomedicine is an international, peerreviewed journal focusing on the application of nanotechnology in diagnostics, therapeutics, and drug delivery systems throughout the biomedical field. This journal is indexed on PubMed Central, MedLine, CAS, SciSearch ${ }^{\mathbb{}}$, Current Contents ${ }^{\mathbb{R}} /$ Clinical Medicine,

\section{Dovepress}

Journal Citation Reports/Science Edition, EMBase, Scopus and the Elsevier Bibliographic databases. The manuscript management system is completely online and includes a very quick and fair peer-review system, which is all easy to use. Visit http://www.dovepress.com/ testimonials.php to read real quotes from published authors. 